\title{
Procalcitonin as a diagnostic tool in lower respiratory tract infections and tuberculosis
}

\author{
A. Polzin*, M. Pletz*, R. Erbes*, M. Raffenberg*, H. Mauch\#, S. Wagner, G. Arndt", H. Lode*
}

Procalcitonin as a diagnostic tool in lower respiratory tract infections and tuberculosis. A. Polzin, M. Pletz, R. Erbes, M. Raffenberg, H. Mauch, S. Wagner, G. Arndt, H. Lode. (C) ERS Journals Ltd 2003.

ABSTRACT: The diagnostic significance of procalcitonin concentrations in lower respiratory tract infections and tuberculosis is not known. A prospective analysis was, therefore, performed in patients with acute exacerbation of chronic bronchitis (AECB), community-acquired pneumonia (CAP), hospital-acquired pneumonia (HAP) and tuberculosis and their procalcitonin levels compared with those of patients with noninfectious lung diseases (controls). In addition, standard inflammatory parameter data were collected.

A prospective clinical study was performed with four different groups of patients and a control group that consisted of patients with noninfectious lung diseases. A total of 129 patients were included: 25 with HAP, 26 CAP, 26 AECB, 27 tuberculosis, and 25 controls. C-reactive protein level, blood cell counts and procalcitonin concentration were evaluated on the first day after onset of clinical and inflammatory symptoms prior to treatment.

The median procalcitonin concentrations in HAP, CAP, AECB and tuberculosis were not elevated in relation to the cut-off level of $0.5 \mathrm{ng} \cdot \mathrm{mL}^{-1}$. In the HAP group, in four of five patients who subsequently died, procalcitonin concentrations of $>0.5 \mathrm{ng} \cdot \mathrm{mL}^{-1}$ were found. In acute lower respiratory infections, such as HAP, CAP and AECB, significantly elevated levels were found in comparison to the control group, but below the usual cut-off level. No differences were observed between tuberculosis and the control group.

Relative to the current cut-off level of $0.5 \mathrm{ng} \cdot \mathrm{mL}^{-1}$, procalcitonin concentration is not a useful parameter for diagnosis of lower respiratory tract infections. However, compared to the control group, there were significantly elevated levels in patients with hospital-acquired pneumonia, community-acquired pneumonia and acute exacerbation of chronic bronchitis below the current cut-off level, which should be further investigated. Eur Respir J 2003; 21: 939-943.

\begin{abstract}
*Dept of Chest and Infectious Diseases and \#Institute for Microbiology, City Hospital Emil von Behring and "Institute for Biometrics and Data Processing, Dept of Veterinary Medicine, Free University of Berlin, Berlin, Germany.
\end{abstract}

Correspondence: H. Lode

City Hospital Emil von Behring

Free University of Berlin

Dept of Chest and Infectious Diseases

Zum Heckeshorn 33

14109 Berlin

Germany

Fax: 493080022623

E-mail: haloheck@zedat.fu-berlin.de

Keywords: C-reactive protein

lower respiratory tract infection

procalcitonin

tuberculosis

white blood cell count

Received: June 262002

Accepted after revision: January 232003
Nosocomial and community-acquired respiratory tract infections are a public health problem of major concern and a leading cause of mortality. Beside clinical signs and symptoms and radiological changes, clinical chemistry parameters are important in confirming diagnosis, as recommended by several guidelines $[1,2]$. In addition to the classical inflammatory parameters of C-reactive protein (CRP) levels and white blood cell (WBC) counts, procalcitonin (PCT) concentration has become a new marker of increasing relevance [3-9].

The usefulness of PCT concentration in diagnosis, and particularly the differential diagnosis of several infectious diseases, is still the matter of some controversy, although it has become generally accepted that PCT is a useful marker for severe systemic bacterial infections such as sepsis [10-13].

In spite of high PCT levels in systemic bacterial, fungal and parasitic infections, no or only slight elevation occurs in viral infections [4]. Also, in the most severe inflammation of noninfectious aetiology, no PCT elevations could be observed, except in severe acute pancreatitis $[14,15]$ and inhalation injuries in burns [16].

In the current prospective study, the utility of pretreatment PCT levels in discriminating between infectious and noninfectious lung diseases as well as between different types of lower respiratory tract infection (community-acquired pneumonia (CAP), hospital-acquired pneumonia (HAP), acute exacerbation of chronic bronchitis (AECB) and tuberculosis (TB)) was investigated.

\section{Patients and methods}

\section{Study subjects}

Between February 1999-June 2001, consecutive patients with suspected bacterial respiratory tract infections participated in the present study at the City Hospital Emil von Behring, Berlin, Germany.

Spontaneous early morning sputum or bronchial secretion was obtained from every patient and analysed microbiologically according to German quality standards in microbiological diagnostics.

Of 174 enrolled patients, 45 had to be excluded because of positive sepsis criteria, pleuritis, acute respiratory distress syndrome, aspiration and empyema. In addition, one patient with small cell lung cancer was excluded because elevated PCT levels have been reported in this condition [17].

After analysis of all diagnostic parameters, the remaining 
Table 1.-Patient characteristics

\begin{tabular}{lccc}
\hline Group & $\begin{array}{c}\text { Subjects } \\
\mathrm{n}\end{array}$ & $\begin{array}{c}\text { Mean age } \\
\text { yrs }\end{array}$ & $\begin{array}{c}\text { Females/males } \\
\mathrm{n}\end{array}$ \\
\hline HAP & 25 & 63.1 & $6 / 19$ \\
CAP & 26 & 57.2 & $11 / 15$ \\
AECB & 26 & 64.5 & $8 / 18$ \\
TB & 27 & 45.2 & $8 / 19$ \\
Control & 25 & 48.4 & $10 / 15$ \\
\hline
\end{tabular}

HAP: hospital-acquired pneumonia; CAP: community-acquired pneumonia; AECB: acute exacerbation of chronic bronchitis; TB: tuberculosis.

129 patients (table 1) were stratified on the basis of American Thoracic Society criteria [2] into the following four groups. 1) CAP: history and clinical signs (i.e. fever $>38.0^{\circ} \mathrm{C}$ or $<36.1^{\circ} \mathrm{C}$, crackles on auscultation and purulent sputum), presence of typical chest radiographical findings and leukocytosis with $>10 \times 10^{9}$ cells $\cdot \mathrm{L}^{-1}$ or leukopenia with $<4 \times 10^{9}$ cells $\cdot \mathrm{L}^{-1} ; 2$ ) HAP: the criteria mentioned above with onset $>48 \mathrm{~h}$ after admission to hospital; 3) AECB: history of chronic bronchitis according to World Health Organization criteria [18] and increases in at least two symptoms of dyspnoea, sputum production and sputum purulence [19]; and 4) TB: positive sputum Ziehl-Neelsen staining and infiltration/cavitation on chest radiography. The control group consisted of patients with noninfectious lung diseases, i.e. alveolitis, fibrosis and sarcoidosis. For all patients, the Acute Physiology, Age, and Chronic Health Evaluation score was calculated to verify the severity of disease.

After approval by the local ethics committee, in accordance with German law, written informed consent was obtained from all subjects.

\section{Study design}

The trial was a prospective clinical study with four patient groups and a control group, and was performed at the City Hospital Emil von Behring. PCT and CRP levels and WBC count with differential blood cell counts were determined on the first day after onset of clinical symptoms before treatment was started.

\section{Methods}

PCT concentration was determined using an immunoluminometric assay (BRAHMS Diagnostica, Berlin, Germany). The test required $2-3 \mathrm{~h}$ and $20 \mu \mathrm{L}$ serum or plasma. The assay used two monoclonal antibodies, one directed against part of the katacalcin sequence of PCT (residues 96-106) as capture antibody and the second recognising part of the calcitonin sequence (residues 70-76) as tracer antibody. During incubation, both antibodies reacted with PCT in a sandwich manner. After several washing procedures, tracer remaining in the test tube was measured using a luminometer; the intensity of the luminescence signal is directly proportional to the PCT concentration of the serum sample. The PCT concentration was quantified by comparison with a standard curve. The assay sensitivity is $0.1 \mathrm{ng} \cdot \mathrm{mL}^{-1}$. Interassay and intra-assay variability at high and low concentration were $<8$ and $<7 \%$, respectively. The upper normal limit was fixed at $0.5 \mathrm{ng} \cdot \mathrm{mL}^{-1}[20]$. Serum $(5-10 \mathrm{~mL})$ was collected from each patient on day 1. Plasma was separated, divided and frozen (at $-80^{\circ} \mathrm{C}$ ) until assay for PCT. CRP levels and other parameters were measured directly at the Institute for Microbiology and Immunology and Laboratory Medicine,
City Hospital Emil von Behring, on the same day. According to standard procedures, CRP level was determined via a turbidimetric assay using polyclonal goat antihuman antibodies (Tina-Quant $₫$ ) (HITACHI 717; Roche Diagnostics $\mathrm{GmbH}$, Mannheim, Germany). WBC count and differential blood cell counts were determined by flow cytometry, according to standard procedures (MaxM; Coulter Beckmann, Krefeld, Germany).

\section{Statistics}

The distributions of serum concentrations for PCT of the five groups are presented as boxplots. Medians and 95\% confidence intervals are tabulated. The boxplots show 25th, 50th and 75th percentiles, minima, maxima, outliers and extreme cases. Outliers are 1.5-3 times the interquartile range from the end of a box; extreme cases are more than threetimes the interquartile range from the end of the box. The null hypothesis "the five groups are independent samples from identical populations" was evaluated by means of the Kruskal-Wallis test. If the null hypothesis is rejected $(\alpha=0.05)$, all possible pairs of groups are compared by means of a Dunn test with $\alpha$-adjustment according to Holm. In order to check whether there was a significant difference between patients with positive bacteriology (CAP, HAP, AECB) and patients with negative bacteriology with regard to CRP, WBC or PCT levels, a Mann-Whitney test for unpaired samples was performed.

The diagnostic accuracy of PCT concentration in discriminating pneumonia from other infectious (i.e. AECB and TB) and noninfectious lung diseases was evaluated by receiver operating characteristic (ROC) analysis. True-positive rates calculated at various cut-off values were plotted on a vertical axis and false-positive rates were plotted on the horizontal axis. Optimal discrimination is defined by minimal false-negative and false-positive results.

\section{Results}

The median PCT concentrations in HAP, CAP, AECB and TB were not elevated relative to the normal cut-off level of $0.5 \mathrm{ng} \cdot \mathrm{mL}^{-1}$ (table 2, fig. 1). The upper limit of the $95 \%$ confidence interval was $<0.5 \mathrm{ng} \cdot \mathrm{mL}^{-1}$ in all groups except for the HAP group, in which it was $0.62 \mathrm{ng} \cdot \mathrm{mL}^{-1}$. Elevated PCT values above the recommended cut-off level were not detected in the control group, TB group or patients with AECB. Ten of the 25 HAP patients and one of the 26 CAP patients exhibited elevated PCT levels. Only five of the 11 patients with elevated PCT levels had a confirmed bacterial aetiology.

Despite the fact that no increase in median PCT concentration above the currently recommended cut-off level was determined, significant differences in relation to absolute PCT concentration were found between the lower respiratory tract infections, with the exception of $\mathrm{TB}$ and the control group (table 3 ).

Based on the findings that patients with pneumonia exhibited higher PCT levels than patients with other lung diseases, investigation of whether PCT is a useful marker for discrimination of pneumonia from AECB, TB and noninfectious lung diseases was undertaken. ROC analysis revealed that optimal discrimination between pneumonia and other lung diseases could be performed at a suggested cut-off point of $0.245 \mathrm{ng} \cdot \mathrm{mL}^{-1}$ with a sensitivity of 0.58 and specificity of 0.91 (fig. 2).

In contrast to PCT, increased median levels of CRP were found in all treatment groups; in the control group, 54\% of values were not above the limit (cut-off $5 \mathrm{mg} \cdot \mathrm{L}^{-1}$ ) (table 2$)$. In 
Table 2. - Procalcitonin (PCT) and C-reactive protein (CRP) concentrations, white blood cell (WBC) count, and Acute Physiology, Age and Chronic Health Evaluation (APACHE) II score in all groups ${ }^{\#}$

\begin{tabular}{lcccc}
\hline & $\begin{array}{c}\mathrm{PCT} \\
\mathrm{ng} \cdot \mathrm{mL}^{-1}\end{array}$ & $\begin{array}{c}\mathrm{CRP} \\
\mathrm{mg} \cdot \mathrm{L}^{-1}\end{array}$ & $\begin{array}{c}\text { WBC count } \\
\mathrm{cells} \cdot \mathrm{ng}^{-1} \cdot \mathrm{mL}^{-1}\end{array}$ & APACHE II \\
\hline HAP & $0.46(0.27-0.62)$ & $183.0(130.0-239.0)$ & $14.1(11.1-18.7)$ & $19.0(16.0-23.0)$ \\
CAP & $0.22(0.13-0.31)$ & $124.0(49.0-165.0)$ & $13.5(11.3-15.1)$ & $13.5(12.0-16.0)$ \\
AECB & $0.19(0.13-0.22)$ & $11.0(5.0-28.0)$ & $10.9(9.3-14.6)$ & $15.0(14.0-16.0)$ \\
TB & $0.14(0.13-0.19)$ & $50.5(32.4-75.0)$ & $8.0(6.5-11.2)$ & $5.0(4.0-7.0)$ \\
Controls & $0.11(0.09-0.15)$ & $5.0(3.2-17.0)$ & $6.7(5.4-9.1)$ & $4.0(3.0-6.0)$ \\
\hline
\end{tabular}

Data are presented as median (95\% confidence interval). HAP: hospital-acquired pneumonia; CAP: community-acquired pneumonia; AECB: acute exacerbation of chronic bronchitis; TB: tuberculosis; controls: noninfectious lung diseases. ${ }^{\#}$; normal values: $\mathrm{PCT}<0.5 \mathrm{ng} \cdot \mathrm{mL}^{-1} ; \mathrm{CRP}<5 \mathrm{mg} \cdot \mathrm{mL}^{-1}$; WBC count $4.0-10.0$ cells $\cdot \mu \mathrm{L}^{-1}$; APACHE II score $0-6$.

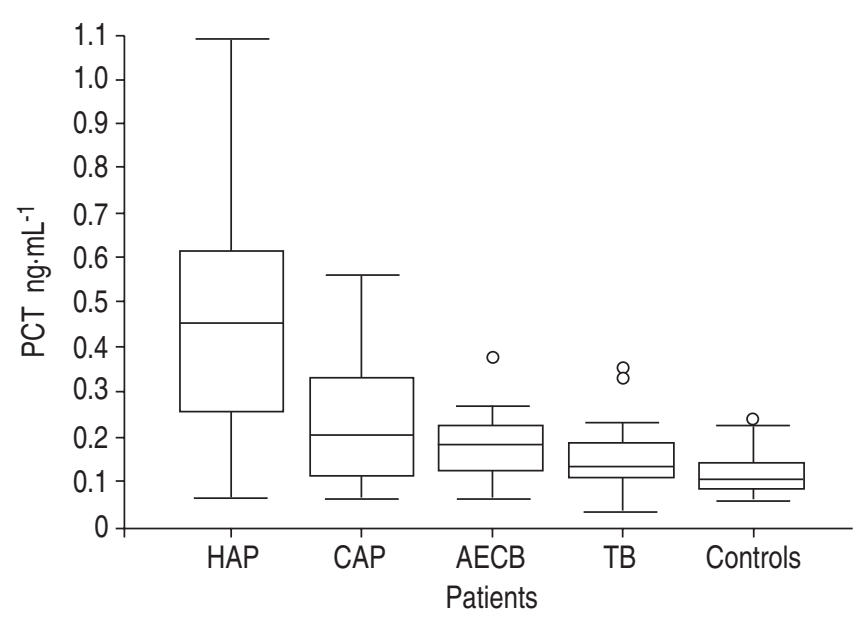

Fig. 1. - Boxplots showing procalcitonin (PCT) concentration in patients with hospital-acquired pneumonia (HAP; n=25), communityacquired pneumonia (CAP; $n=26$ ) acute exacerbation of chronic bronchitis (AECB; $n=26$ ) and tuberculosis $(\mathrm{TB} ; \mathrm{n}=27)$, and controls (noninfectious lung diseases; $\mathrm{n}=25$ ). The boxplots show 25 th, 50th and 75th percentiles and minima, maxima and outliers $(\bigcirc)$. Extreme and outlier values in the HAP group $\left(9.6\right.$ and $\left.1.49 \mathrm{ng} \cdot \mathrm{mL}^{-1}\right)$ and the extreme value in the CAP group $\left(2.31 \mathrm{ng} \cdot \mathrm{mL}^{-1}\right)$ are not shown.

AECB, there was only moderate elevation of CRP levels in comparison to the HAP and CAP groups.

Significant differences in CRP concentration between AECB and pneumonia were measured $(\mathrm{p}<0.01)$. No differences in CRP concentration between the AECB and control groups were observed $(p=0.21)$ (table 3$)$.

Similar results were seen with the WBC count (cut-off 4-10 cells $\cdot \mu \mathrm{L}^{-1}$ ) (table 2 ). Interestingly, no differences were found between TB and the noninfectious controls $(p=0.56)$. Between pneumonia and AECB, no significant differences could be detected $(\mathrm{p}=0.51)$ (table 2$)$. Positive bacteriology was

Table 3. - Comparison of procalcitonin (PCT) and C-reactive protein (CRP) concentrations, and white blood cell (WBC) count between groups and controls

\begin{tabular}{lccc}
\hline Group & \multicolumn{3}{c}{ p-value } \\
\cline { 2 - 4 } & PCT & CRP & WBC count \\
\hline HAP & $<0.01$ & $<0.01$ & $<0.01$ \\
CAP & 0.01 & $<0.01$ & $<0.01$ \\
AECB & 0.04 & 0.2 & $<0.01$ \\
TB & 0.5 & $<0.01$ & 0.56 \\
\hline
\end{tabular}

HAP: hospital-acquired pneumonia; CAP: community-acquired pneumonia; AECB: acute exacerbation of chronic bronchitis; TB: tuberculosis; controls: noninfectious lung diseases. ${ }^{\#}$ : Kruskal-Walis test. confirmed in $68 \%$ of cases in the HAP group, in $56 \%$ in the CAP group and in $53.8 \%$ in the AECB group. No differences were found between positive and negative bacteriology in the HAP, CAP and AECB groups with regard to PCT, CRP and WBC levels $(\mathrm{p}=0.81$ for PCT, $\mathrm{p}=0.39$ for $\mathrm{CRP}$ and $\mathrm{p}=0.43$ for WBCs).

Two patients in the HAP group and one in the CAP group who showed abnormally elevated levels of PCT, defined as "extreme value", were observed. In the HAP group, one patient with an elevated PCT value, categorised as "outlier value", was detected.

The extreme value in the CAP group (PCT $1.2 \mathrm{ng} \cdot \mathrm{mL}^{-1}$ ) occurred in a patient with positive bacteriology (Staphylococcus aureus) who developed respiratory insufficiency requiring intubation and transfer to the intensive care unit $24 \mathrm{~h}$ after hospital admission.

One extreme value in the HAP group (PCT $2.31 \mathrm{ng} \cdot \mathrm{mL}^{-1}$ ) was evident in a patient with nonsmall cell lung cancer, meningeal metastasis, positive bacteriology ( $S$. aureus and Klebsiella pneumoniae) and respiratory insufficiency. The patient died 5 days after PCT measurement as a result of cardiac arrest due to respiratory failure. The other extreme value (PCT $\left.9.6 \mathrm{ng} \cdot \mathrm{mL}^{-1}\right)$ in this group was recorded in a patient 3 days after a volume reduction operation.

The outlier value in the HAP group (PCT $1.49 \mathrm{ng} \cdot \mathrm{mL}^{-1}$ ) occurred in a patient with nonsmall cell lung cancer, and was measured on the first day after pneumonectomy.

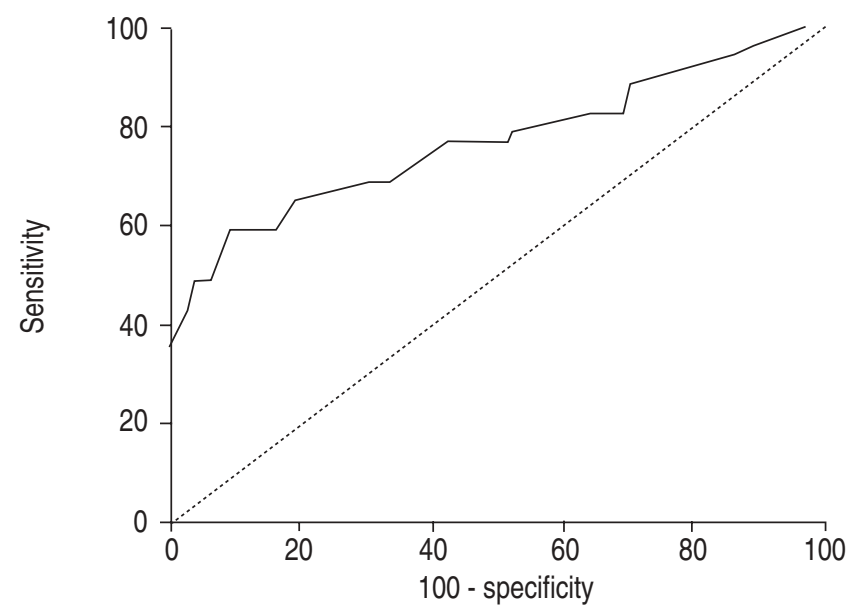

Fig. 2.-Receiver operating characteristic (ROC) curve ( - ) for discrimination of pneumonia (hospital- and community-acquired) from other infectious (tuberculosis and acute exacerbation of chronic bronchitis) and noninfectious lung diseases. The cut-off point showing optimal sensitivity/specificity was $0.245 \mathrm{ng} \cdot \mathrm{mL}^{-1}$ (sensitivity 0.58 , specificity 0.91 ). ……. $45^{\circ}$ diagonal (the more a curve approaches this diagonal the less accurate the test). 


\section{Discussion}

In HAP, CAP and, to a lesser extent, AECB, but not TB, significantly elevated median PCT levels were found compared to controls. However, median PCT levels in all groups were below the recommended cut-off level of $0.5 \mathrm{ng} \cdot \mathrm{mL}^{-1}$. Therefore, according to the present study, PCT concentration seems not to be particularly useful for the detection of lower respiratory tract infections e.g. CRP. Similar results were obtained by HEDLUND and HANSSON [21], who compared CRP and PCT levels in CAP in adults. However, Moulin et al. [22] described a superiority of PCT over CRP concentration in paediatric patients with CAP. In the recent publication of BRUNKHORST et al. [23], different results, with elevated PCT levels in patients with severe pneumonia, were demonstrated. In contrast to the present study, the latter study included only patients with severe pneumonia, who were treated in the intensive care unit. This could also be a reason for the elevated PCT levels. Although diagnostic value has not been proved, PCT concentration was found to be of moderate prognostic value [23].

Concerning the usefulness of PCT concentration as a diagnostic parameter, HAUSFATER et al. [24] showed that sensitivity was low (in contrast to a high specificity) with the use of a cutoff level of $0.5 \mathrm{ng} \cdot \mathrm{mL}^{-1}$, but that improved sensitivity could be obtained after reducing the cut-off level. They concluded that the PCT threshold could be lower than that proposed for critically ill patients. Similar results were seen in the present study, in which PCT levels showed significantly elevated values below the cut-off level in patients with pneumonia and AECB compared to the control group. However, HAUSFATER et al. [24] included patients from an emergency department who had heterogeneous infectious diseases. It was suspected that PCT could be useful for screening emergency-department patients with more severe infections, since good correlation of PCT concentration was seen with the prognosis of patients suffering systemic infections [24].

Furthermore, FLEISCHHACK et al. [25] found a higher sensitivity and specificity of PCT concentration in comparison to CRP concentration in the diagnosis of high-risk Gramnegative bacteraemia in neutropenic paediatric patients.

To date, there are no published studies addressing the impact of PCT concentration in AECB. Despite the fact that AECB has been primarily determined to be a local inflammation and that PCT concentration is considered mainly a marker of systemic bacterial infections, elevated levels below the usual cut-off concentration were observed in AECB compared to the control group. Interestingly, there was no difference in WBC count and CRP level between AECB and noninfectious controls.

In TB, no elevated levels of PCT were detected. The same was observed by ZARKA et al. [26], who investigated PCT levels in 49 patients with CAP, TB and Pneumocystis-carinii pneumonia.

PCT concentration is believed to be a sufficient parameter for differentiation between severe systemic bacterial and nonbacterial infections [27]. However, in the present study, no differences in PCT level in connection with bacterial aetiology were found for patients with respiratory infections (HAP, CAP and AECB). A similar conclusion was drawn by TOIKKA et al. [28], who investigated PCT levels in children with viral and bacterial pneumonia.

With respect to the outlier and extreme values, different aspects need to be considered. In regard to the outlier and one of the extreme values in the HAP group, postoperative pneumonia should be taken into account. The higher levels of PCT are possibly related to the postoperative situation, fully described in literature pertaining to such elevated postoperative PCT levels, and particularly in situations involving thoracic surgery [29]. In the case of the patient with the other extreme value in the HAP group, the diagnosis pertained to nonsmall cell lung cancer, as well as an early stage of sepsis, which developed some days after the patient had been included in the study. To the best of the present authors' knowledge, there are no studies relating PCT concentration to lung cancer. Studies addressing in-vitro environments provided evidence of secretion of various calcitonin precursor molecules originally produced by small cell lung cancer cells [17]. The developing septic condition may also be an explanation for the higher PCT concentration.

In the case pertaining to the extreme value in the CAP group, the clinical condition of the patient was found to deteriorate progressively. As a result, in later stages, the criterion of sepsis was evident, explaining the high level of PCT [4, 30, 31].

In summary, compared to the control group, significantly elevated PCT concentrations were found in patients with HAP, CAP and AECB below the recommended cut-off level. Therefore, it could be discussed whether PCT concentration could become a useful parameter in the diagnosis of lower respiratory tract infections after a reduction in the cut-off level. ROC analysis based on the present data demonstrated that, in a patient with a PCT concentration of $<0.245 \mathrm{ng} \cdot \mathrm{mL}^{-1}$, pneumonia can be ruled out with a probability of $91 \%$.

\section{Conclusion}

In acute respiratory infections such as hospital-acquired pneumonia, community-acquired pneumonia and acute exacerbation of chronic bronchitis, significantly elevated procalcitonin levels were found in comparison to the control group, but below the recommended cut-off level of $0.5 \mathrm{ng} \cdot \mathrm{mL}^{-1}$. Therefore, in regard to the currently recommended cut-off level, procalcitonin was not a useful parameter in the diagnosis of lower respiratory tract infections in the present study. Furthermore, in tuberculosis patients, neither elevated procalcitonin concentrations nor a significant difference to the control group were found.

\section{References}

1. European Study on Community-acquired Pneumonia (ESOCAP) Committee. Guidelines for management of adult communityacquired lower respiratory tract infections. Eur Respir $J$ 1998; 11: 986-991.

2. Niederman MS, Mandell LA, Anzueto A, et al. Guidelines for the management of adults with community-acquired pneumonia. Diagnosis, assessment of severity, antimicrobial therapy, and prevention. Am J Respir Crit Care Med 2001; 163: $1730-1754$.

3. Aouifi A, Piriou V, Bastien $\mathrm{O}$, et al. Usefulness of procalcitonin for diagnosis of infection in cardiac surgical patients. Crit Care Med 2000; 28: 3171-3176.

4. Assicot M, Gendrel D, Carsin H, Raymond J, Guilbaud J, Bohuon C. High serum procalcitonin concentrations in patients with sepsis and infection. Lancet 1993; 341: 515-518.

5. Gerard Y, Hober D, Assicot M, et al. Procalcitonin as a marker of bacterial sepsis in patients infected with HIV-1. J Infect 1997; 35: 41-46.

6. Maruna P, Nedelnikova K, Gurlich R. Physiology and genetics of procalcitonin. Physiol Res 2000; 49: Suppl. 1, S57-S61.

7. Pusch F, Wildling E, Freitag H, Weinstabl C. Procalcitonin as a diagnostic marker in patients with aspiration after closed head injury. Wien Klin Wochenschr 2001; 113: 676-680.

8. Sudhoff T, Giagounidis A, Karthaus M. Evaluation of 
neutropenic fever: value of serum and plasma parameters in clinical practice. Chemotherapy 2000; 46: 77-85.

9. von Landenberg P, Shoenfeld Y. New approaches in the diagnosis of sepsis. Isr Med Assoc J 2001; 3: 439-442.

10. de Werra I, Jaccard C, Corradin SB, et al. Cytokines, nitrite/ nitrate, soluble tumor necrosis factor receptors, and procalcitonin concentrations: comparisons in patients with septic shock, cardiogenic shock, and bacterial pneumonia. Crit Care Med 1997; 25: 607-613.

11. Endo S, Kasai T, Inada K. Evaluation of procalcitonin levels in patients with systemic inflammatory response syndrome as the diagnosis of infection and the severity of illness. Kansenshogaku Zasshi 1999; 73: 197-204.

12. Schroder J, Staubach KH, Zabel P, Stuber F, Kremer B. Procalcitonin as a marker of severity in septic shock. Langenbecks Arch Surg 1999; 384: 33-38.

13. Yukioka H, Yoshida G, Kurita S, Kato N. Plasma procalcitonin in sepsis and organ failure. Ann Acad Med Singapore 2001; 30: 528-531.

14. Kylanpaa-Back ML, Takala A, Kemppainen E, Puolakkainen P, Haapiainen R, Repo H. Procalcitonin strip test in the early detection of severe acute pancreatitis. Br J Surg 2001; 88: 222-227.

15. Mandi Y, Farkas G, Takacs T, Boda K, Lonovics J. Diagnostic relevance of procalcitonin, IL-6, and sICAM-1 in the prediction of infected necrosis in acute pancreatitis. Int $J$ Pancreatol 2000; 28: 41-49.

16. Nylen ES, $\mathrm{O}^{\prime}$ Neill W, Jordan MH, et al. Serum procalcitonin as an index of inhalation injury in burns. Horm Metab Res 1992; 24: 439-443.

17. Cate CC, Pettengill OS, Sorenson GD. Biosynthesis of procalcitonin in small cell carcinoma of the lung. Cancer Res 1986; 46: 812-818.

18. Definition and classification of chronic bronchitis for clinical and epidemiological purposes. A report to the Medical Research Council by their Committee on the Aetiology of Chronic Bronchitis. Lancet 1965; 1: 775-779.

19. Anthonisen NR, Manfreda J, Warren CP, Hershfield ES, Harding GK, Nelson NA. Antibiotic therapy in exacerbations of chronic obstructive pulmonary disease. Ann Intern Med 1987; 106: 196-204.

20. Meisner M. Labor. In: Procalcitonin (PCT). 3rd Edn.
Stuttgart, New York, Georg Thieme Verlag, 2000; pp. 162175.

21. Hedlund J, Hansson LO. Procalcitonin and C-reactive protein levels in community-acquired pneumonia: correlation with etiology and prognosis. Infection 2000; 28: 68-73.

22. Moulin F, Raymond J, Lorrot M, et al. Procalcitonin in children admitted to hospital with community acquired pneumonia. Arch Dis Child 2001; 84: 332-336.

23. Brunkhorst FM, Al Nawas B, Krummenauer F, Forycki ZF, Shah PM. Procalcitonin, C-reactive protein and APACHE II score for risk evaluation in patients with severe pneumonia. Clin Microbiol Infect 2002; 8: 93-100.

24. Hausfater P, Garric S, Ayed SB, Rosenheim M, Bernard M, Riou B. Usefulness of procalcitonin as a marker of systemic infection in emergency department patients: a prospective study. Clin Infect Dis 2002; 34: 895-901.

25. Fleischhack G, Kambeck I, Cipic D, Hasan C, Bode U. Procalcitonin in paediatric cancer patients: its diagnostic relevance is superior to that of C-reactive protein, interleukin 6 , interleukin 8 , soluble interleukin 2 receptor and soluble tumour necrosis factor receptor II. Br J Haematol 2000; 111: 1093-1102.

26. Zarka V, Valat C, Lemarie E, et al. Procalcitonine sérique et pathologie infectieuse respiratoire. Rev Pneumol Clin 1999; 55: 365-369.

27. Oczenski W, Fitzgerald RD, Schwarz S. Procalcitonin: a new parameter for the diagnosis of bacterial infection in the perioperative period. Eur J Anaesthesiol 1998; 15: 202-209.

28. Toikka $\mathrm{P}$, Irjala $\mathrm{K}$, Juven $\mathrm{T}$, et al. Serum procalcitonin, C-reactive protein and interleukin-6 for distinguishing bacterial and viral pneumonia in children. Pediatr Infect Dis J 2000; 19: 598-602.

29. Meisner M, Tschaikowsky K, Hutzler A, Schick C, Schuttler J. Postoperative plasma concentrations of procalcitonin after different types of surgery. Intensive Care Med 1998; 24: 680684.

30. Carlet J. Rapid diagnostic methods in the detection of sepsis. Infect Dis Clin North Am 1999; 13: 483-494, xi.

31. Herrmann W, Ecker D, Quast S, Klieden M, Rose S, Marzi I. Comparison of procalcitonin, sCD14 and interleukin-6 values in septic patients. Clin Chem Lab Med 2000; 38: $41-46$. 